\title{
Water doesn't mind the gap
}

It could be the world's longest liquid bridge: researchers have coaxed water into leaping a 25-millimetre gap between two regular glass beakers in a gravity-defying stunt. The engineering feat could involve a hitherto unknown microstructure of water, the researchers say.

"Nobody would expect stable bridges to form," says Elmar Fuchs, a physical chemist at Graz University of Technology in Austria.

Fuchs's team applied up to 25,000 volts across electrodes placed in two beakers filled nearly to the brim with distilled water. Within a millisecond, water crawled up to the edge of one beaker and, in a burst of sparks, leapt across the gap between them. As the researchers moved the beakers apart, the bridge grew. The resulting thin cylinder of water stood for up to 45 minutes (E. C. Fuchs et al. J. Phys. D 40, 6112-6114; 2007).

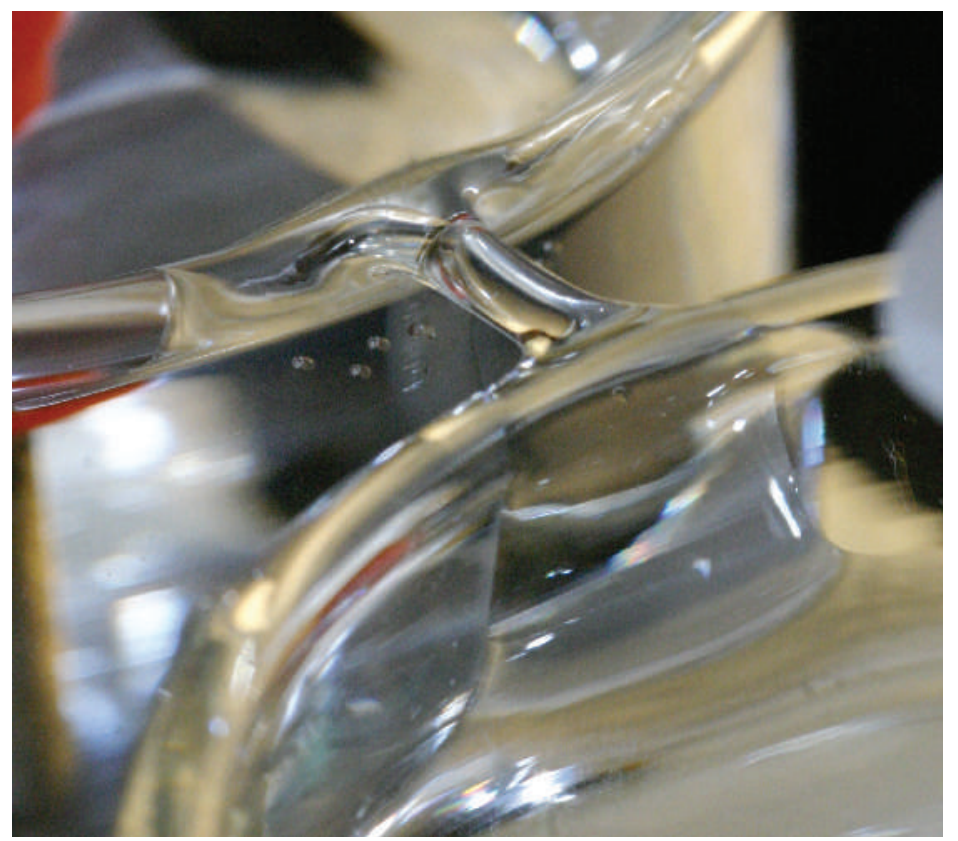

Researchers have managed to create a bridge of water between two beakers.

hydrogens and the negative oxygen. In an electric field, water molecules line up. In this case, Chang theorizes, the molecules orient themselves to form a cylindrical bridge. The repulsion between similarly charged atoms effectively wedges the bridge in place, he suggests.

Using a charged glass wand, Fuchs and his colleagues could bend the bridge from side to side. They found that water actually flowed through the centre of the bridge, from one beaker to another. The team analysed the moving water and found that it was denser than the surrounding bridge. Fuchs says he doesn't fully understand the phenomenon, but speculates that the denser water coalesces into microstructures that somehow strengthen the bridge. The group plans to carry out X-ray experi-

Chang uses electric fields to expel water droplets from the tips of capillaries in coneshaped jets called electrosprays. He says that the water bridge relies on similar phenomena, on a bigger scale. The bridge takes advantage of the well-understood polarity of water molecules - due to the positively charged ments to determine the molecular structure of the water flowing through the bridge.

The bridge lasted until too many dust particles and ions had entered the water, increasing the current across the bridge. It heated up and eventually ruptured.

Eric Hand

\section{Nukes: next generation not fit for certification}

The Bush administration's controversial plan to replace its cold war stockpile of nuclear weapons with a new, 'safer' nuclear arsenal has met with fresh criticism. An independent panel of scientists has concluded that "substantial work remains" before the next generation of warheads is fit for certification.

In a report released on 10 ctober, the JASON defence advisory group, which consults regularly for the government on a range of technical issues, said there was insufficient peer review over the design for the Reliable Replacement Warhead (RRW). The RRW is to be built without compromising a 1992 US moratorium on all nuclear tests. The report also calls for an extensive battery of non-nuclear 'subcritical' tests to ensure that the new warhead will work as required.

Panel-member Roy Schwitters, a physicist at the University of Texas in Austin, says that the design's "approach is valid", but "in lieu of new underground tests, we feel that peer review should have a bigger role" in the certification process. At present, the internal peer-review process of the three involved labs looks only at aspects of the design, not the entire system, he says.

The agency responsible for maintaining the US nuclear stockpile - the National Nuclear Security Administration (NNSA)
— claims that the RRW would be more dependable than the current generation of cold war weapons. It would also contain new safeguards that would prevent its use if it fell into the hands of terrorists. But arms-control advocates say the programme is a costly handout to the nation's nuclear weapons laboratories and, they say, questions about the RRW's design could lead to renewed testing.

The report is a further setback for the programme, which is already under enormous congressional scrutiny, says Jeffrey Lewis, an

\section{arms-control expert at the New} America Foundation in Washington DC. "It suggests that the NNSA did a poor job in putting together a certification plan," he says.

This week, the NNSA also reported that its dismantlement of deployed warheads had accelerated by $146 \%$ over the 2007 fiscal year - three times greater than it had anticipated. Under the 2002 Strategic Offensive Reductions Treaty with Russia, the United States is committed to reducing its warheads to between 1,700 and 2,200 by 2012.

Geoff Brumfiel 